\title{
An investigation of the \\ hyperaminoaciduria in phenylketonuria associated with the feeding of certain commercial low-phenylalanine preparations
}

\author{
BY BARBARA E. CLAYTON, A. F. HEELEY* \\ AND MARY HEELEY \\ Department of Chemical Pathology, The Hospital for Sick Children and \\ Institute of Child Health, London, WCI \\ (Received 24 October 1969-Accepted 29 December 1969)

\begin{abstract}
1. Hypertryptophanaemia, hypertryptophanuria and to a lesser degree a generalized hyperaminoaciduria were observed in phenylketonuric patients receiving certain commercial low-phenylalanine diets containing DL-tryptophan.

2. The generalized hyperaminoaciduria was associated with the ingestion of acid hydrolysates of protein, but not with the ingestion of enzymic hydrolysates or D-tryptophan.

3. Alanine recovered from the urine of these treated patients had a D-isomer content of approx. $50 \%$. This amount of urinary D-alanine could be derived from the ingestion of an acid hydrolysate of protein in which the amino acids had racemized to the extent of $2-3 \%$.
\end{abstract}

The low-phenylalanine preparations (Minafen; Trufood Ltd, and Cymogran; Allen and Hanburys Ltd), used in this hospital for the treatment of phenylketonuria contain a commercially prepared acid hydrolysate of casein to which certain essential amino acids, including DL-tryptophan, have been added. Phenylketonuric children receiving this diet frequently have raised plasma levels of tryptophan and also a generalized hyperaminoaciduria.

Although D-methioninuria has been described in a premature infant who was being fed a commercial food preparation which was supplemented with DL-methionine (Efron, McPherson, Shih, Welsh \& MacCready, 1969), there appears to be no published information relating to the cause of the aminoaciduria in children receiving commercial low-phenylalanine preparations.

It was thought that the hyperaminoaciduria might be the result of ingesting small amounts of D-amino acids formed during the acid hydrolysis of casein; after absorption these would be rapidly excreted by the kidneys. Alternatively it was possible that large amounts of D-tryptophan from the diet, on passing into the blood stream, might interfere with the renal tubular reabsorption of other amino acids, in which event an L-aminoaciduria would be evident.

In view of the nutritional importance of this problem an investigation of the hyperaminoaciduria following the ingestion of low-phenylalanine diets was undertaken.

* Present address: Ida Darwin Hospital, Fulbourn, Cambridge. 


\section{EXPERIMENTAL AND RESULTS}

Diets

Investigations were performed on phenylketonuric children receiving a phenylalanine-controlled diet in which most natural protein was replaced by a special preparation low in phenylalanine: Cymogran (Allen and Hanburys Ltd), an acid hydrolysate of casein with added DL-tryptophan, Albumaid (Scientific Hospital Supplies Ltd), an acid hydrolysate of ox blood with added L-tryptophan, and Lofenalac (Mead Johnston Ltd), an enzymic hydrolysate of casein with added L-tryptophan. The composition of these foods is given in Table $I$. The diets included phenylalanine-free foods, fruit, vegetables and the minimum amount of natural protein necessary to provide the essential requirement for phenylalanine (Report to the Medical Research Council of the Conference on Phenylketonuria, I963; Clayton, Francis \& Moncrieff, 1965).

Table I. Approximate composition of commercial low-phenylalanine preparations

\begin{tabular}{|c|c|c|c|c|c|c|}
\hline \multirow[b]{2}{*}{ Preparation } & \multirow{2}{*}{$\begin{array}{c}\text { Calories } \\
\text { provided } \\
\text { by } 100 \mathrm{~g} \\
\text { (kcal) }\end{array}$} & \multicolumn{4}{|c|}{ Composition (g/I00 g powder) } & \multirow[b]{2}{*}{$\begin{array}{c}\text { Phe (mg/roog } \\
\text { powder) }\end{array}$} \\
\hline & & $\begin{array}{c}\text { Protein } \\
\text { hydrolysate }\end{array}$ & Fat & $\begin{array}{l}\text { Carbo- } \\
\text { hydrate }\end{array}$ & $\begin{array}{l}\text { Other con- } \\
\text { stituents }\end{array}$ & \\
\hline Albumaid & 370 & 40 & $\circ$ & 55 & 5 & Nil \\
\hline Cymogran & 400 & 40 & 9 & 43 & 8 & $\begin{array}{l}\text { Not more } \\
\text { than ro }\end{array}$ \\
\hline Lofenalac & 450 & 15 & 18 & 57 & 10 & About 80 \\
\hline
\end{tabular}

\section{Chemical standards}

D-Tryptophan, D-alanine and DL-alanine, obtained from Koch-Light Laboratories Ltd, were at least $99 \%$ pure.

\section{Collection of samples and chemical methods}

Capillary blood used for all determinations was obtained by finger prick. In nonphenylketonuric children the samples were obtained when blood was being collected for haemoglobin determinations. Random samples of urine were obtained from most of the subjects. Tryptophan was measured in plasma and urine by the method of Denckla $\&$ Dewey (1967), $\alpha$-amino nitrogen in urine by the method of Goodwin (1968) and creatinine in urine by the method of Owen, Iggo, Scandrett \& Stewart (I954). Urinary amino acids were separated on Whatman No. 3 MM paper by high-

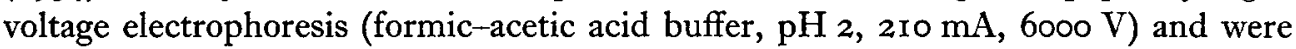
made visible by staining the paper with ninhydrin (Smith, I969).

Alanine was recovered from a urine sample collected $3 \mathrm{~h}$ after the ingestion of Cymogran and was examined for its D-isomer content. Urine was concentrated fourfold by evaporation and $0.25 \mathrm{ml}$ was applied to Whatman No. $3 \mathrm{MM}$ paper, in amounts of Io $\mu 1$ applied along strips $2.54 \mathrm{~cm}$ wide. The amino acids were separated by highvoltage electrophoresis and alanine was located by staining one of the strips with 
ninhydrin. The alanine-containing areas of the remaining strips were cut out and eluted evernight with $50 \%(\mathrm{v} / \mathrm{v})$ aqueous ethanol. The eluate was filtered and evaporated to dryness. The residue was dissolved in $0.5 \mathrm{ml}$ water, and when $10 \mu \mathrm{l}$ of this solution were analysed by high-voltage electrophoresis, only one ninhydrin-staining band was visible and was due to alanine. The alanine was measured quantitatively by elution from the paper by the method described by Atfield \& Morris (1960). To $0.4 \mathrm{ml}$ of this solution was added $0 . \mathrm{I} \mathrm{ml}$ of lyophilized hog kidney D-amino acid oxidase (Koch-Light Laboratories Ltd) dissolved in 0.1 M-sodium pyrophosphate buffer, $\mathrm{pH} 8 \cdot 2(8.5 \mathrm{mg} / \mathrm{ml}$ buffer $)$. The reaction was carried out in an atmosphere of oxygen for $3 \mathrm{~h}$ at $37^{\circ}$. When identical amounts of recovered alanine were incubated with the oxidase for more than $3 \mathrm{~h}$, no further destruction of alanine was observed, showing that the reaction was complete. The protein of the reaction mixture was coagulated by adjusting to $\mathrm{pH} 5$ with dilute acetic acid and immersing the reaction tube in a boiling water bath for I min. Coagulated protein was separated by centrifugation and the supernatant fluid was decanted. The protein residue was washed with $0.5 \mathrm{ml}$ of $\circ \cdot \mathrm{I}$ M-sodium acetate buffer, $\mathrm{pH}_{5}$, centrifuged again, and the supernatant fractions were decanted. The combined supernatant fractions were evaporated to dryness and redissolved in $0.4 \mathrm{ml}$ water. Equivalent amounts of DL-alanine and D-alanine were treated in the same way, as was a reaction blank in which the alanine solution was replaced by $0.4 \mathrm{ml}$ water. The amounts of alanine remaining in the reaction mixture after incubation with oxidase were determined by the method of Atfield \& Morris (1960).

\section{Subjects}

The studies were performed on a total of twenty-seven boys and twenty-four girls aged from 4 months to II. 5 years receiving a phenylalanine-controlled diet for the treatment of phenylketonuria. In addition, fifty similar children who were in hospital and receiving a normal diet following tonsillectomy were investigated. None of them had a metabolic disorder, and results for them provided control values. Two healthy adult volunteers were men aged $3^{\circ}$ and $3^{2}$ years.

\section{Determination of plasma tryptophan in phenylketonuric and control children}

Tryptophan was measured in seventy-six samples of plasma collected at various times throughout the day from fifty phenylketonouric patients whose diet included Cymogran, and in fifty-two samples from fifty control children.

Results are shown in Fig. I. The mean plasma tryptophan value was twice as high in the phenylketonuric children as in the controls.

\section{Excretion of tryptophan and $\alpha$-amino nitrogen in urine}

Tryptophan, $\alpha$-amino nitrogen and creatinine were determined on random samples of urine obtained from the phenylketonuric children receiving Cymogran and from the controls. Results are shown in Table 2, the excretion of tryptophan and $\alpha$-amino nitrogen being expressed as $\mathrm{mg} / \mathrm{g}$ creatinine. The $\alpha$-amino nitrogen due to tryptophan has been subtracted from the total urinary $\alpha$-amino nitrogen. The $\alpha$-amino nitrogen 
Table 2. Effect of Cymogran on the excretion of tryptophan and $\alpha$-amino nitrogen* in random samples of urine from control children on a normal diet and from phenylketonuric children receiving Cymogran

\begin{tabular}{|c|c|c|c|c|c|c|}
\hline \multirow[b]{3}{*}{ Subjects } & \multirow{3}{*}{$\begin{array}{l}\text { No. of } \\
\text { subjects }\end{array}$} & \multirow[b]{3}{*}{ Diet } & \multicolumn{4}{|c|}{ Urinary excretion ( $\mathrm{mg} / \mathrm{g}$ creatinine) } \\
\hline & & & \multicolumn{2}{|c|}{ Tryptophan } & \multicolumn{2}{|c|}{$\alpha$-Amino nitrogen* } \\
\hline & & & Mean & Range & Mean & Range \\
\hline Controls & I6 & Normal & $18 \cdot 8$ & $13 \cdot 1-25 \cdot 2$ & 178 & $120-221$ \\
\hline Phenylketonurics & 10 & Cymogran & 869 & $126-2455$ & 436 & $108-1800$ \\
\hline
\end{tabular}

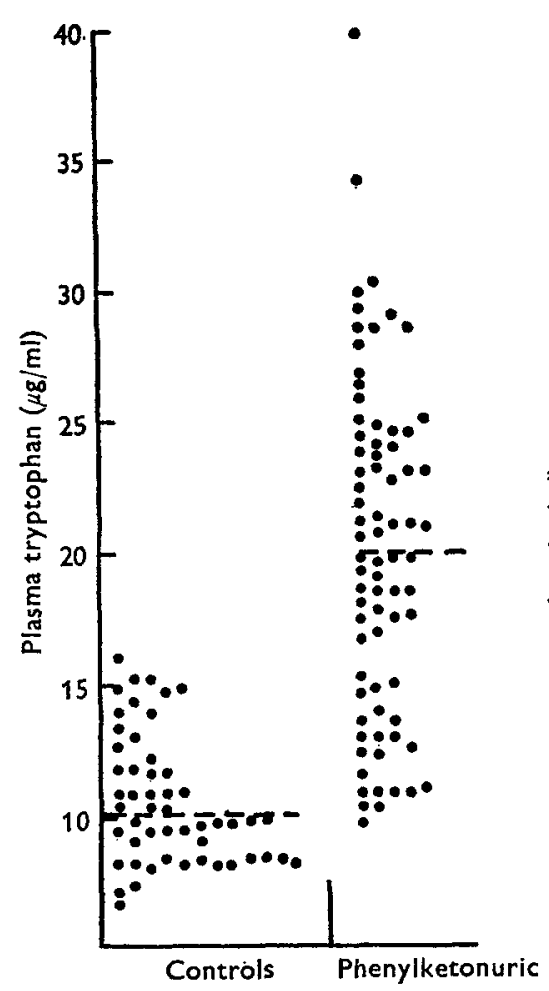

Fig. I

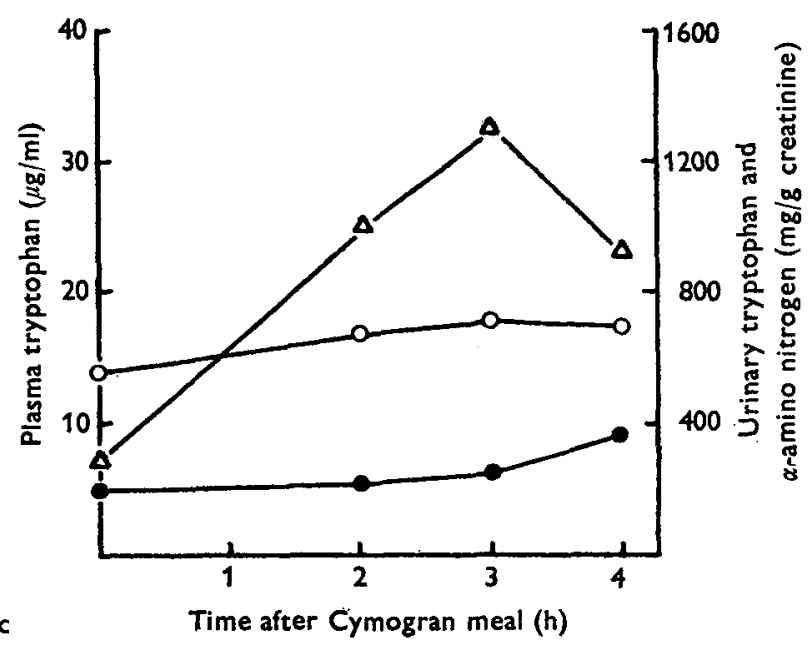

Fig. 2

Fig. I. Plasma tryptophan concentration in control children receiving a normal diet and in phenylketonuric children receiving Cymogran (a low-phenylalanine preparation). -..., mean value.

Fig. 2. Plasma and urinary tryptophan and urine $\alpha$-amino nitrogen concentrations in one phenylketonuric child following the ingestion of Cymogran (patient E). $O-O$, plasma tryptophan; $\triangle-\Delta$, urinary tryptophan; - urinary $\alpha$-amino nitrogen.

excretion by the controls was within normal limits which are wide (Goodwin, I968). The phenylketonuric patients excreted considerably more tryptophan and $\alpha$-amino nitrogen than the controls. 


\section{Plasma and urinary tryptophan and urinary $\alpha$-amino nitrogen following ingestion of Cymogran}

Single specimens of urine and samples of plasma were collected from five phenylketonuric patients (A-E) 2-4 h after breakfast containing Cymogran. Large variations were found in the excretion of urinary tryptophan and $\alpha$-amino nitrogen (see Table 3 ). Serial studies were performed on one patient (patient E) for $4 \mathrm{~h}$ after Cymogran, and results are shown in Fig. 2.

Table 3. Plasma and urinary tryptophan and urinary $\alpha$-amino nitrogen concentrations in five phenylketonuric children at various times after a meal containing Cymogran

\begin{tabular}{|c|c|c|c|c|}
\hline \multirow[b]{2}{*}{ Subject } & \multirow[b]{2}{*}{$\begin{array}{c}\text { Time after } \\
\text { meal } \\
\text { (h) }\end{array}$} & \multirow[b]{2}{*}{$\begin{array}{c}\text { Plasma } \\
\text { tryptophan } \\
(\mu \mathrm{g} / \mathrm{ml})\end{array}$} & \multicolumn{2}{|c|}{$\begin{array}{l}\text { Urinary excretion }(\mathrm{mg} / \mathrm{g} \\
\text { creatinine) }\end{array}$} \\
\hline & & & Tryptophan & $\begin{array}{l}\alpha \text {-Amino } \\
\text { nitrogen* }\end{array}$ \\
\hline A & 2 & $16 \cdot 5$ & 487 & 108 \\
\hline B & $2 \cdot 5$ & $26 \cdot 8$ & 609 & 390 \\
\hline C & 3 & $29 \cdot 3$ & I304 & 439 \\
\hline D & $3 \cdot 5$ & $22 \cdot 7$ & 2455 & I 800 \\
\hline $\mathbf{E}$ & 4 & I7 5 & 942 & 344 \\
\hline
\end{tabular}

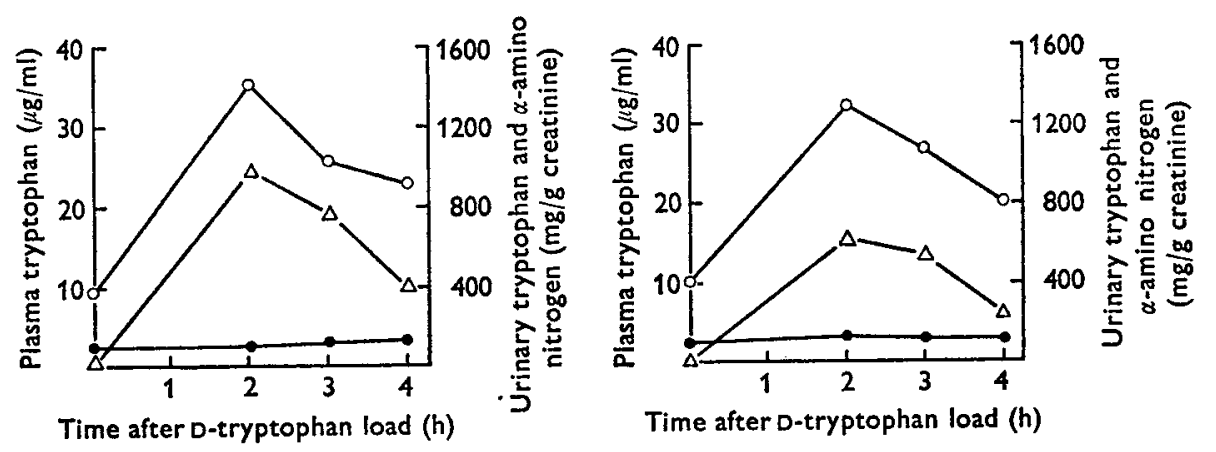

Fig. 3. Plasma and urinary tryptophan and urine $\alpha$-amino nitrogen concentrations following the ingestion of D-tryptophan by two healthy adult males. $\mathrm{O}-\mathrm{O}$, plasma tryptophan; $\triangle-\triangle$, urinary tryptophan; $-\infty$, urinary $\alpha$-amino nitrogen.

Effect of administration of D-tryptophan on plasma and urinary tryptophan and urinary $\alpha$-amino nitrogen. Two adults were given D-tryptophan, $15 \mathrm{mg} / \mathrm{kg}$ body-weight, mixed with a normal breakfast. There was a marked increase in plasma and urinary tryptophan levels (see Fig. 3) but no detectable increase in urinary $\alpha$-amino nitrogen (not including tryptophan).

Effect of Albumaid and Lofenalac. Determinations performed before and after breakfast on two children who were receiving Albumaid (one of whom usually received Cymogran) showed an increased urinary excretion of $\alpha$-amino nitrogen but little increase in urinary tryptophan, and surprisingly, an increase in plasma tryptophan. Results for one patient $(\mathrm{F})$ are shown in Table 4 .

Breakfast containing Lofenalac as the source of dietary nitrogen was then fed to the 
phenylketonuric patient $(\mathrm{F})$ who usually received Albumaid, and urine and plasma were examined. No significant increase in either the plasma or urinary tryptophan or urinary $\alpha$-amino nitrogen was observed (see Table 4 ).

Chromatography of amino acids in urine. The hyperaminoaciduria associated with the ingestion of Cymogran and Albumaid was examined quantitatively by high-voltage electrophoresis on paper. Prominent features of the hyperaminoaciduria following the ingestion of Cymogran were markedly increased levels of alanine, the branched-chain amino acids and occasionally the group of basic amino acids, and following ingestion of Albumaid an increased lysine excretion. Other amino acids were increased to lesser degree, with the exception of glycine and proline which were always within normal limits. The urinary amino acid patterns following the ingestion of D-tryptophan by the adult males were normal.

Table 4. Plasma and urinary tryptophan and urinary $\alpha$-amino nitrogen concentrations in patient $F$ before and after a meal containing Albumaid and Lofenalac respectively

\begin{tabular}{|c|c|c|c|}
\hline \multirow[b]{2}{*}{$\begin{array}{c}\text { Time after } \\
\text { meal } \\
\text { (h) }\end{array}$} & \multirow[b]{2}{*}{$\begin{array}{l}\text { Plasma } \\
\text { tryptophan } \\
(\mu \mathrm{g} / \mathrm{ml})\end{array}$} & \multicolumn{2}{|c|}{$\begin{array}{l}\text { Urinary excretion } \mathrm{mg} / \mathrm{g} \\
\text { creatinine }\end{array}$} \\
\hline & & Tryptophan & $\begin{array}{l}\alpha \text {-Amino } \\
\text { nitrogen } *\end{array}$ \\
\hline \multicolumn{4}{|c|}{ Patient F: Albumaid } \\
\hline Fasting & $8 \cdot 0$ & 17 & 406 \\
\hline 2 & - & 37 & 331 \\
\hline 3 & $19 \cdot 9$ & 49 & 416 \\
\hline 4 & $16 \cdot 8$ & 27 & 533 \\
\hline \multicolumn{4}{|c|}{ Patient F: Lofenalac } \\
\hline Fasting & II $\cdot 3$ & 25 & 218 \\
\hline 2 & - & 22 & $26 I$ \\
\hline 3 & $9: 7$ & 21 & 200 \\
\hline 4 & - & I 5 & 286 \\
\hline
\end{tabular}

Effect of D-amino acid oxidase on alanine recovered from urine following the ingestion of Cymogran. Since alanine is separated from other amino acids by high-voltage paper electrophoresis at $\mathrm{pH}_{2}$, this amino acid was eluted from the electrophoretograms of a urine sample collected $3 \mathrm{~h}$ after the ingestion of Cymogran; $0.04 \mathrm{mg}$ alanine was recovered from I $\mathrm{ml}$ of urine. Approximately $50 \%$ of this alanine was destroyed when incubated with an excess of $\mathrm{D}$-amino acid oxidase. Under identical reaction conditions, an equivalent amount of authentic DL-alanine was destroyed to the same extent. It was concluded therefore that approx. $50 \%$ of the alanine in the urine was of the $\mathrm{D}$-form, and since the amount of alanine per $\mathrm{mg}$ creatinine was approximately twice that found in normal urine, it was also concluded that the hyperalaninuria associated with the ingestion of Cymogran was due entirely to the presence of D-alanine in the urine. 


\section{DISCUSSION}

The results presented support the hypothesis that the hyperaminoaciduria resulting from the ingestion of certain low-phenyalanine preparations is due to the presence of small amounts of D-amino acid in the diet. The hyperaminoaciduria was observed when children were fed acid-hydrolysed protein preparations whether or not they contained added DL-tryptophan. The ingestion of an enzymic hydrolysate of casein produced no increase in urinary $\alpha$-amino nitrogen. The ingestion of $\mathrm{D}$-tryptophan alone produced no increase in the excretion of $\alpha$-amino nitrogen, other than that due to D-tryptophan. Alanine isolated from the urine of a phenylketonuric child who was being treated with Cymogran was shown to contain the D-isomer in an amount which accounted for the hyperalaninuria. These observations support those of Schendel, Antonis \& Hansen (1959) who on feeding L- and DL-amino acids to infants with kwashiorkor found that most of the D-amino acids were excreted in the urine.

From experimental evidence (for a review see Martin \& Synge, 1945) it is apparent that acid hydrolysis of protein causes a certain amount $(2-3 \%)$ of racemization of the constituent amino acids. The presence of DL-tryptophan (50\% D-tryptophan) in certain preparations resulted in a mean increase in urinary tryptophan above normal levels by a factor of 46 . Assuming that other D-amino acids are absorbed from the gut and excreted by the kidney in a manner similar to D-tryptophan, the observed mean increase in urinary $\alpha$-amino nitrogen following the ingestion of acid-hydrolysates of casein would be accounted for by the presence of other $D$-amino acids in the diet to the extent of $2-3 \%$.

The question remains to be answered to what extent $\mathrm{D}$-amino acids might be detrimental to human development, particularly when incorporated in the diet of the newborn. There are marked species differences in the availabilities of the D-amino acids for growth and the maintenance of nitrogen balance, and most of the long-term experimental work relates to animals. Albanese, Snyderman, Lein, Smetak \& Vestal (1949) produced evidence that, in human infants, DL-tryptophan might have some untoward effect on development when used as a supplement to diets low in tryptophan.

Though there is no clear evidence that $\mathrm{D}$-amino acids administered over long periods are detrimental to human development, it would seem advisable to exclude them from synthetic diets intended for use with infants and children.

We are grateful to the Physicians of the Hospital for Sick Children for permission to investigate their patients and to the Nursing Staff for their careful collection of urine specimens. Financial support by the Nuffield Foundation is gratefully acknowledged.

\section{REFERENCES}

Albanese, A. A., Snyderman, S. E., Lein, M., Smetak, E. M. \& Vestal, B. (1949). F. Nutr. $\mathbf{3}^{8}, 215$. Atfield, G. N. \& Morris, C. J. O. R. (1960). In Protides of the Biological Fluids; Proceedings of the Eighth Colloquium, Bruges p. 78. [H. Peeters, editor.] Amsterdam: Elsevier Publishing Co.

Clayton, B., Francis, D. \& Moncrieff, A. (1965). Br. med. F. i, 54.

Denckla, W. D. \& Dewey, H. K. (1967). F. Lab. clin. Med. 69, 160.

Efron, M. L., McPherson, T. C., Shih, V. E., Welsh, C. F. \& MacCready, R. A. (I969). Am. F. Dis. Child. II7, I04. 
Goodwin, J. F. (1968). Clinica chim. Acta 2r, 23 I.

Martin, A. J. P. \& Synge, R. L. M. (1945). Adv. Protein Chem. 2, I.

Owen, J. A., Iggo, B., Scandrett, F. J. \& Stewart, C. P. (1954). Biochem. F. 58, 426.

Report to the Medical Research Council of the Conference on Phenylketonuria (1963). Br. med. $9 . \mathrm{i}$, I69I.

Schendel, H. E., Antonis, A. \& Hansen, J. D. L. (1959). Pediatrics, Springfield 23, 662.

Smith, I. (I969). In Chromatographic and Electrophoretic Techniques 3rd. ed. Vol. I, p. I19. [I. Smith, editor.] London: William Heinemann Medical Books Ltd. 